\begin{tabular}{|ll|}
\hline Received & $:$ 30 Maret 2019 \\
Revised & $: 4$ April 2019 \\
Accepted & $: 22$ April 2019 \\
Online & $: 28$ April 2019 \\
Published & $:$ 30 April 2019 \\
\hline
\end{tabular}

\title{
PHYSICS HYPNOTEACHING : A LITERATUR REVIEW
}

\author{
Allika Nur Ramdina Syahas ${ }^{1)}$ \\ ${ }^{1}$ Fakultas Teknik, Universitas Negeri Jakarta \\ Email : allikasyahas@gmail.com
}

\begin{abstract}
This paper aims to test whether hypnoteaching can eliminate students' negative thoughts towards learning physics, which further increases student interest and active learning. One of the lessons that many students have difficulty with is physics. The data in this paper is sourced from the study of relevant theories such as reference books, journals, and research. Based on studies that have been obtained, states that hypnoteaching is a way that can be applied by teachers in overcoming the problem of learning physics learning. The results of the literature study prove that the application of hypnoteaching is proven to be helpful in overcoming student learning problems and touching students' physics learning problems without the student's direct realizing due to using the student's subconscious approach. Hypnoteaching in the literature has also proven to be a solution in removing students' mental blocks when starting learning and is very easy to use by teachers in dealing with students with various kinds of learning problems in physics, ranging from feeling stupid, lazy, feeling physics is useless, pessimistic excess, and problems other physics learning. Hypnoteaching is easily applied by all teachers because there is no need to use any tools in doing this method so it is suitable for use in all corners of Indonesian schools.
\end{abstract}

Kata Kunci: Physics, Hypnoteaching, Mental Block.

\begin{abstract}
Abstrak
Karya tulis ini bertujuan untuk menguji apakah hypnoteaching dapat menghilangkan pikiran negatif siswa terhadap pembelajaran fisika, yang selanjutnya meningkatkan minat dan keaktifan belajar siswa. Salah satu pelajaran yang siswa banyak mengalami kesulitan adalah fisika. Data dalam karya tulis ini bersumber dari kajian teori yang relevan seperti buku referensi, jurnal, dan penelitian. Berdasarkan kajian yang sudah didapatkan, menyatakan bahwa hypnoteaching merupakan cara yang bisa diterapkan oleh guru dalam mengatasi masalah belajar pembelajaran fisika. Hasil studi literatur membuktikan bahwa penerapan hypnoteaching ini terbukti membantu dalam mengatasi masalah belajar siswa dan menyentuh masalah belajar fisika siswa tanpa disadari langsung oleh murid bersangkutan karena menggunakan pendekatan alam bawah sadar siswa. Hypnoteaching secara literatur juga terbukti menjadi solusi dalam menghilangkan mental-block siswa saat memulai pembelajaran dan sangat mudah digunakan oleh guru dalam menghadapi murid dengan berbagai macam masalah belajar dalam fisika, mulai dari merasa bodoh, malas, merasa fisika tidak berguna, pesimis berlebih, dan masalah pembelajaran fisika lainnya. Hypnoteaching mudah diterapkan oleh semua guru karena tidak perlu menggunakan alat bantu apapun dalam melakukan metode ini sehingga sangat cocok untuk digunakan di seluruh pelosok sekolah indonesia.
\end{abstract}

Kata Kunci: Fisika, Hypnoteaching, Mental Block. 


\section{PENDAHULUAN}

Manusia mampu menjangkau bagian yang sangat luar biasa. Manusia dapat terbang ke atas dunia dengan roket dan menyelam ke dasar laut dengan kapal selam. Namun, satu pertanyaan muncul, apakah orang yang menyokong ini hanya orang yang setara einstein dan manusia lain tidak. Ada manusia yang memiliki Kemampuan bermacam-macam,ada yang lemah saat diberi deretan angka, namun sangat lihai memainkan kuas, ada yang sangat gugup ketika diperintahkan untuk berpidato tapi sangat mahir jika menyelesaikan pekerjaan komputer. Karena sifat inilah manusia memiliki potensi untuk menjadi genius dalam bidang masingmasing. Ada kemungkinan semua anak memiliki potensi seperti einstein di bidangnya masing masing, inilah tugas guru untuk mengeksploitasi kemampuan anak agar dapat menemukan kemampuannya (Navis, 2013).

Pendekatan Empirisme menyatakan bahwa manusia pada dasarnya terlahir ke dunia tidak memiliki apapun kecuali masih bersih layaknya kertas kosong, atau yang biasa dikenal tabula rasa. Empirisme itu sendiri berasal dari kata Yunani yaitu "Empiris" yang berartipengalaman inderawi. Oleh karena itu empirisme adalah faham yang memilih pengalaman sebagai sumber utama pengenalan baik pengalaman lahiriah yang menyangkut dunia maupun pengalaman batiniah yang menyangkut pribadi manusia. Empirisme menolak anggapan bahwamanusia telah membawa fitrah pengetahuan dalam dirinya ketika dilahirkan.

Proses mewarnai kertas kosong adalah hal yang mengintegrasikan semua elemen dalam kehidupan manusia, mulai pendidikan dari keluarga, sekolah, dan masyarakat. Ketiga hal harus menjadi pena yang baik dalam pewarnaan kertas kosong tersebut. Beberapa kondisi menunjukkan bahwa pendidikan kita belum mampu membangun karakter bangsa. Karena, hingga saat ini praktik pendidikan yang terjadi dikelas-kelas tidak lebih darilatihan-latihan skolastik, seperti mengenal, membandingkan, melatih,dan menghafal(Surachmad Winarno, 2003).

Seorang guru harus memenuhi kualifikasi-kualifikasi yang telah ditentukan dalam undangundang, agar guru dapat melaksanakan tugas dan perannya dengan baik dan benar sebagai pelaksana pendidikan. Salah satu kualifikasi yang harus dipenuhi oleh guru ialah kompetensi. Adapun kompetensi yang harus dimiliki oleh guru yaitu, kompetensi pedagogik, kepribadian, sosial, dan profesional. Mengenai hal ini, telah dijelaskan dalam undang-undang BAB IV Pasal 10 ayat 1, bahwa: "Kompetensi guru sebagaimana dimaksud dalam Pasal 8 meliputi kompetensi pedagogik, kompetensi kepribadian, kompetensi sosial, dan kompetensi profesional yang diperoleh melalui pendidikan profesi".

Sebuah survey oleh zenius.net mengenai "Survei Pandangan Siswa/i tentang Sekolah, Guru, dan Orang Tua". Survei ini dilaksanakan mulai 22 September 2014 hingga 15 Desember 2014. Zenius berhasil mengumpulkan jawaban dari 1.340 responden pelajar dari seluruh pelosok Indonesiasehingga kita bisa memperoleh data yang lebih representatif tentang pelajar Indonesia secara keseluruhan. Dari data didapatkan bahwa Fisika menjadi pelajaran tidak disukai pertama disusul oleh Matematika dan Sejarah. Data ini menunjukkan bahwa memang siswa memiliki rasa percaya diri yang rendah bahkan sebelum memulai pembelajaran fisika. Selain itu Hasil Trends inMathematics and Science Study (TIMSS) tahun 2011 untuk bidang sains, Indonesia berada diurutan ke-40 dari 42 negara dengan skor 406. Hal ini menunjukkan pencapaian prestasi belajar siswa Indonesia di bidang sains berada pada posisi rendah. Dari data diatas dapat disimpulkan bahwa fisika menjadi pelajaran yang tidak disukai oleh siswa. Data ini menunjukkan bahwa memang siswa memiliki masalah belajar dalam pembelajaran fisika, bahkan bisa jadi masalahnya ada sebelum siswa memulai pembelajaran fisika.

Dalam menyelesaikan masalah ini, pendidik harus mengerti dan dapat mempraktikkan konsep pedagogi yang efektif agar tujuan pendidikan tercapai. Peran pendidik dalam keberhasilan suatu proses pembelajaran sangatlah besar. Tiap-tiap pendidik mempunyai cara 
yang berbeda-beda dalam menyampaikan pengajaran. Berdasarkan pengamatan dalam pembelajaran fisika, diperoleh data bahwa masih banyak siswa yang kurang termotivasi dalam mempelajari fisika. Pada umumnya, mereka memandang bahwa fisika itu mata pelajaran yang penuh dengan rumus-rumus yang sulit, dan hitungan yang rumit. Hampir $60 \%$ siswa secara tidak sadar telah menyatakan "saya tidak bisa, fisika itu sulit, saya takut salah". Hal ini menunjukkan bahwa mereka telah menghipnosis diri sendiri untuk "tidak bisa" mempelajari fisika. Hal ini berakibat pada minat dan keaktifan siswa, serta rata-rata nilai fisika belum memenuhi target yang diharapkan.

Jika siswa sejak awal pembelajaran sudah mengalami mental-block dengan mengatakan fisika sulit, maka dapat dipastikan siswa akan semakin tidak ingin belajar fisika dan sejelas apapun guru menjelaskan tidak akan dipahami siswa. Hypnoteaching merupakan perpaduan pengajaran yang melibatkan pikiran sadar dan bawah sadar. Hypnoteaching ini merupakan metode pembelajaran yang kreatif, sekaligus unik, dan imajinatif. Hypnoteachingmenyentuh pikiran bawah sadar siswa sehingga guru dapat menyalurkan motivasi-motivasi selama pembelajaran, dengan harapan siswa mampu menghancurkan mental-blockketika belajar fisika tersebut.

Berdasarkan kajian tentang cara mengatasi masalah belajar siswa dalam pembelajaran fisika, maka dalam pembelajaran fisikaakan diterapkan Metodehypnoteaching untuk membuka pikiran negatif siswa-siswa atau mental-blockselama pembelajaran fisika berlangsung.

\section{METODE PENELITIAN}

Penulisan karya tulis ilmiah Hypnoteaching ini termasuk jenis penelitian studi literatur. Data-data yang digunakan penulis bersumber dari literatur yang relevan dengan kasus permasalahan. Beberapa diantaranya bersumber dari buku referensi, jurnal, dan abstrak hasil penelitian. Menurut Sarwono (2006) beberapa sumber kepustakaan yang dapat digunakan oleh peneliti yaitu abstrak hasil penelitian, indeks, review, jurnal, dan buku referensi

\section{HASIL DAN PEMBAHASAN}

\section{Permasalahan Pembelajaran Fisika}

Kesulitan belajar merupakan kondisi saat siswa mengalami hambatan-hambatan tertentu untuk mengikuti proses pembelajaran dan mencapai hasil belajar secara optimal. Kesulitanbelajar adalah segala sesuatu yang membuat tidak lancar (lambat) ataumenghalangi seseorang dalam mempelajari, memahami sertamenguasai sesuatu untuk dapat mencapai tujuan. Adanya kesulitanbelajar dapat ditandai dengan prestasi yang rendah atau di bawah rata-ratayang dicapai oleh kelompok kelas, hasil yang dicapai tidakseimbang dengan usaha yang dilakukan dan lambat dalam melakukantugas belajar. Siswa yang mengalami kesulitan belajar akan sukardalam menyerap materi-materi pelajaran yang disampaikan oleh gurusehingga ia akan malas dalam belajar. Selain itu siswa terindikasi mengalami masalah belajarsaat terus-menerus tidak dapat menguasaimateri, menghindari pelajaran, serta mengabaikan tugas-tugas yangdiberikan guru.Salah satu pelajaran yang siswa banyak mengalami kesulitan adalah pelajaran fisika, hal ini didukung dengan sebuah survey oleh zenius.net mengenai "Survei Pandangan Siswa-siswi tentang Sekolah, Guru, dan Orang Tua". Survei ini dilaksanakan mulai 22 September 2014 hingga 15 Desember 2014. Zenius berhasil mengumpulkan jawaban dari 1.340 responden pelajar dari seluruh pelosok Indonesiasehingga kita bisa memperoleh data yang lebih representatif tentang Pelajar Indonesia secara keseluruhan. Dari data tersebut dapat disimpulkan bahwa Fisika menjadi pelajaran pertama paling tidak disukai disusul Matematika dan Sejarah. Selain itu Hasil Trends in Mathematics and Science Study (TIMSS) tahun2011 untuk bidang sains, Indonesia berada diurutan ke-40 dari 42 negara dengan skor 406 .Hal ini menunjukkan pencapaian prestasi belajar siswa Indonesia di bidang sains berada pada posisi rendah. Dari data diatas dapat disimpulkan bahwa fisika 
menjadi pelajaran yang tidak disukai oleh siswa. Data ini menunjukkan bahwa memang siswa memiliki masalah belajar dalam pembelajaran fisika, bahkan bisa jadi masalahnya ada sebelum siswa memulai pembelajaran fisika.

\section{Penerapan Hypnoteaching dalam Pembelajaran Fisika}

Mengatasi permasalahan dalam pembelajaran fisika merupakan harapan bagi semua pendidik fisika, karena pada dasarnya fisika memang merupakan pembelajaran yang banyak melibatkan logika dan nalar siswa, sehingga cenderung membosankan. Jika siswa sejak awal pembelajaran sudah mengalami mental-block dengan mengatakan fisika sulit, maka dapat dipastikan siswa akan semakin tidak ingin belajar fisika dan sejelas apapun guru menjelaskan tidak akan dipahami siswa. Banyak cara yang telah dilakukan pendidik untuk dapat mengatasi permasalahan belajar fisika, namun permasalahan siswa semakin hari semakin kompleks dan untuk mempermudah pemecahan masalah ini perlu adanya koordinasi sinergis dengan disiplin ilmu lain yang relevan. Salahsatu hasil koordinasi sinergis pembelajaran fisika dengan disiplin ilmu lain dapat diwujudkan dengan Hypnoteaching. Hypnoteaching merupakan perpaduan pengajaran yang melibatkan pikiran sadar dan bawah sadar. Hypnoteaching ini merupakan metode pembelajaran yang kreatif, sekaligus unik, dan imajinatif. Hypnoteaching bisa dipadukan dan selaras dengan pembelajaran fisika yang mengedepankan akal dan imajinasi siswa saat pembelajaran berlangsung. Metode pembelajaran ini menyajikan materi pelajaran dengan menggunakan bahasa-bahasa bawah sadar, karena menurut ilmu psikologi alam bawah sadar lebih besar dominasinya terhadap cara kerja otak. Hypnoteaching merupakan gabungan dari lima metode belajar mengajar, seperti quantum learning, accelerate learning, power teaching, NeuroLinguistic Programming (NLP) dan hypnosis (Suwandi, 2010). Mengajar dengan metode hypnoteaching merupakan solusi bagi permasalahan belajar siswa pada pembelajaran fisika karena siswa akan diajak mengeksplorasi alam bawah sadarnya dan menghancurkan mental-block yang terbentuk diawal pembelajaran.

\section{Pentingnya Memecahkan Mental-Block}

Mahardika (2015) menjelaskan bahwa hypnoteaching memiliki manfaat yang sangat besar bagi perkembangan belajar peserta didik, salah satunya adalah membuat siswa gemar dan keranjingan (ketagihan) belajar sehingga hal tersebut dapat mendongkrak prestasinya. Dalam mengatasi masalah belajar dan menerapkan hypnoteaching, peran guru sangatlah penting. Guru adalah satu-satunya sosok yang bisa mewujudkan cita-cita dari hypnoteaching, yakni membuat peserta didik giat dan semangat belajar. Itulah kenapa guru harus menguasai hypnoteaching.

Hypnotis adalah seni berkomunikasi untuk menembus faktor kritis sehingga memudahkan seseorang menerima informasi baru pada pikiran bawah sadarnya. Hipnotis dalam pembelajaran ditujukan untuk mengefektifkan proses pembelajaran menjadi lebih menyenangkan dan fokus dengan menggunakan mekanisme pikiran, faktor kritis, serta gelombang otak secara ilmiah dan alamiah terjadi melalui interaksi guru dengan peserta didik (Mahardika, 2015).

Dalam proses pembelajaran, hipnotis dibutuhkan karena dapat menghancurkan mental-block. Dalam hal ini, mental-blockadalah kondisi mental yang menghambat seseorang dalam mencapai keinginan yang sebenarnya berasal dari beliefatau keyakinan membatasi (L.S., 2010). Pada intinya, mental-block adalah bentuk ketidakyakinan. Selama mental-block tidak diatasi, maka seseorang akan sulit dalam menggapai tujuannya. Mental-blockakan menjadi biang keladi dari pencapaian hidup yang rendah. Mental-block merupakan penghambat utama yang menghalangi seseorang mewujudkan masa depan yang diinginkan (Gunawan, 2009).

Ada beberapa kalimat yang menjadi tanda dari mental-block. Bila mengucapkan kalimat tersebut sekalipun di dalam hati maka anda telah mengalami mental-block. Adapun contoh dari kalimat mentalblockdiantaranya adalah "Oh, saya sudah tahu itu"; "Ah... Teori apalagi ini?"; "Saya tidak membutuhkan itu"; "Sulit sekali"; dan sebagainya (Webe, 2010).

Perlu diketahui bahwa mental-blocksangatperlu dan harus dimusnahkan, terutama pada peserta didik. Sebab, mental-blockakan menghambat seorang peserta didik dalam mencapai keinginannya. Selain itu, mental-blockjuga menghalangi pikiran sadar peserta didik dari tindakan positif yang 
memberdayakannya. Singkatnya, mental-blockyang kemungkinan besar dialami baik oleh para peserta didik maupun guru dapat menghambat proses dan optimalisai pembelajaran (Mahardika, 2015).

\section{Kondisi Hypnotis dalam Proses Pembelajaran}

Hypnoteaching bertujuan untuk mengaplikasikan hipnotis dalam proses pembelajaran atau kegiatan belajar-mengajar. Oleh karena itu, posisi guru dalam hypnoteaching adalah sebagai penghipnotis dan peserta didik sebagai klien. Dalam penerapannya di kelas, hypnoteaching bukan berarti guru menidurkan peserta didik sebagaimana praktik-praktik hipnotis dalam acara hiburan televisi atau hipnotis yang selama ini diyakini masyarakat.

Mengutip dari Andri Hakim, para ahli secara garis besar telah merumuskan ciri-ciri kondisi hipnosis yang dimanfaatkan dalam proses pembelajaran. Berikut lima ciri kondisi hipnosis dalam pembelajaran (Hakim, 2011).

\section{Perhatian yang Terfokus}

Perhatian yang Terpusat. Kondisi hipnosis dapat dibagi menjadi hipnosis ringan (light hypnosis) dan hinposis dalam (deep hypnosis). Proses belajar-mengajar lebih menggunakan teknik light hypnosis. Kondisi fokus saat belajar merupakan kondisi yang dibutuhkan oleh setiap orang agar pikiran tidak bercabang dan tingkat emosional seseorang menjadi stabil. Dalam kondisi hipnosis ringan, gelombang seseorang berada pada light alpha. Proses memindahkan kondisi pikiran beta seseorang (yaitu kondisi ketika gelombang pikir seseorang berkisar antara 24-14 putaran otak per detik) menuju kondisi alpha (yaitu berkisar antara 14-7 putaran otak per detik) sebenarnya sangat diperlukan. Relaksasi sering dilupakan pada saat sesi pembelajaran. Padahal, hal itu merupakan prasyarat seseorang untuk dapat menyerap setiap data, informasi, dan pengetahuan. Sebuah ketegangan meyebabkan seseorang sulit untuk berkonsentrasi dan hasil pembelajaran tidak maksimal.

\section{Relaksasi Fisik}

Relaksasi dapat bekerja mempengaruhi otak untuk mendukung keyakinan seseorang bahwa belajar merupakan kegiatan nyata. Morrison dan Estes (2007) menyatakan bahwa aplikasi skenario dunia nyata merupakan strategi yang efektif untuk mengajarkan IPA sebagai proses. Sebuah proses pengajaran di sekolah merupakan rangkaian kerja antara satu guru dan guru lain. Jika suasana kelas pada pagi hari sudah mengandung aura emosi antara guru dan siswa, dapat dibayangkan bagaimana suasana kelas selanjutnya. Berikut ini merupakan teknik relaksasi yang dapat dipergunakan guru. (a) Self Relaxation (Relaksasi terhadap Diri Sendiri). Sebelum guru memberikan teknik relaksasi di dalam kelas, guru melakukan relaksasi cepat (fast relaxaion). Berikut ini hal yang dilakukan dalam melakukan relaksasi cepat: pengaturan napas, kendalikan pikiran selalu dimulai dengan doa dan afirmasi, dan visualisasi doa dan afirmasi. (b)Student Relaxation (Relaksasi terhadap Siswa). Pada saat guru masuk kelas, biasakan hal yang membuat siswa terasa nyaman dengan menggunakan rumus $5 \mathrm{~S}$, yaitu Salam, Sapa, Senyum, Sopan, dan Santun. Rapport building atau membangun kedekatan merupakan sebuah proses membangun kepercayaan dan keyakinan pegajar, guru, orang tua kepada anak didik, siswa, maupun anakanaknya. Salah satu kunci sukses prestasi siswa

\section{Peningkatan Kemampuan Sebagian atau Seluruh Pancaindra}

Deni Mahardika dalam bukunya mengatakan bahwa dalam proses Hypnoteaching seorang guru harus memvisualisasikan semua pelajaran yang dilakukan guru. Ini bertujuan agar siswa menggunakan seluruh Indra Penerima informasinya dan memudahkan pembelajaran dicapai. Contoh pada materi torsi dan momen inersia guru harus menghadirkan alat peraga berupa jungkit-jungkit dan murid harus merasakan langsung proses yang terjadi di dalamnya.

\section{Pengendalian Refleks dan Aktivitas Fisik}

Dalam pengajaran dikelas, seringkali guru melakukan serangkaian refleks anggota tubuh. Refleks ini bertujuan untuk memodalitas berbagai karakter peserta didik. Peserta didik yang mengandalkan modalitas visual, maka informasi yang didapatkannya cenderung berupa gerakan tubuh pengajar dan akan diserapnya menjadi informasi. Bagi peserta didik yang mengandalkan modalitas kinestetik, maka 
peserta didik akan terfokus pada papan tulis dan apa yang ditulis guru di depan. Sedangkan, untuk peserta didik yang mengandalkan modalitas auditori memiliki tendensi mendengarkan secara serius hal-hal yang dijelaskan gurunya.

5. Respons Peserta Didik sebagai Pengaruh Pascahipnotis

Sulit dan mudahnya peserta didik dalam belajar sebenarnya terletak pada respon yang dihasilkan strategi motivasi kepada peserta didik pada awal proses pembelajaran. Kunci utamanya adalah sugesti yang membawa siswa pada respon positif. Hal ini sebagaimana yang dikatakan Andri Hakim bahwa hasil yang dirasakan dalam sebuah proses hipnotis adalah bagaimana pengaruh sugesti yang diberikan berdampak terhadap aktivitas subjek (peserta didik).

\section{Mengatasi Masalah Belajar Fisika Dengan Hypnoteaching}

Pembelajaran fisika yang tidak disukai dapat disebabkan oleh mental-blockatau disebabkan faktor internal yang terbentuk di awal pembelajaran. Keadaan ini membuat penyampaian ilmu menjadi terhambat, menurut Andri Hakim ada beberapa jurus rahasia hipnotis untuk mengatasi permasalahan belajar siswa dalam proses pembelajaran dalam uraian sebagai berikut.

\section{Locking People in a box pada awal pengajaran}

Cara ini merupakan sebuah metafora atau perumpamaan bahwa sesungguhnya pikiran perlu diarahkan kedalam pola berpikir yang sama. Teknik ini bisa digunakan untuk memotivasi dan mengendalikan peserta didik yang dianggap bermasalah atau kurang berprestasi dalam belajar, teknik ini juga bermanfaat mengatasi berbagai kebiasaan buruk.

Teknik Locking People in a box ini prinsipnya sama seperti tukang sulap, meskipun penonton mengetahui bahwa sulap itu ilusi dan tipuan, mereka tetap terpana dan heran. Bahkan, penonton turut melontarkan pujian yang menunjukkan kekaguman, seperti "Wah, Hebat!" "Luar Biasa", "Keren!", dan sebagainya.

Cara melalukan teknik ini dapat dilakukan diawal untuk memancing kepercayaan diri siswa dan membangun karakter baik pada siswa. Untuk memunculkan motivasi siswa yang paling malas untuk belajar maka dapat dilakukan teknik locking in a box ini di awal pembelajaran. Dalam praktiknya, guru dapat dapat memanggil siswa yang malas tersebut dan memintanya memimpin doa. Pada praktiknya guru bisa mengatakan kalimat sugesti setelah memimpin doa, misal kepada Amir "Bapa percaya bahwa Amir mampu menjadi pemimpin masa depan dan masuk ke universitas terfavorit karena Amir adalah anak yang rajin".

Kalimat tersebut merupakan bagian dari hipnotis yang dapat memotivasi peserta didik yang malas. Dengan kata-kata sugesti seperti ini, pikiran bawah sadar si Amir akan bangkit. Hal tersebut pada akhirnya akan memunculkan sikap dan perilaku yang lebih positif.

\section{The Principle of Attribution di Setiap Akhir Pelajaran}

Teknik The Principle of Attribution dapat dilakukan sebagai langkah persuasif untuk mengarahkan dan memotivasi siswa agar memerhatikan guru kapan saja dan dimana saja. Teknik ini menggunakan kata-kata yang bermakna titipan atau pesan moral. Adapun Contoh dari teknik ini "ibu bangga dengan prestasi belajar kalian semua. Besok, walaupun kita bertemu dengan mata pelajaran berbeda, semangat, konsetrasi, dan kualitas belajar kalian jauh lebih baik dari hari ini. Aamiin”. Teknik The Principle of Attribution dapat juga dilakukan dengan memberikan cerita-cerita motivasi yang memikat siswa atau dapat juga menceritakan cerita orang-orang hebat di masanya.

Sugesti yang diberikan pada akhir pelajaran diharapkan mampu meningkatkan motivasi dan semangat belajar peserta didik di pertemuan selanjutnya. Dengan teknik ini, guru seakan-akan memberikan titipan atau atribut yang menerangkan bahwa kelas dan para peserta didik sekarang sangat baik, pintar, cerdas, dan luar biasa. Sehingga, peserta didik akan mengharapkan hal yang sama terjadi pada pertemuan selanjutnya. 


\section{Anchoring untuk Mengatasi Peserta didik Bermasalah di kelas}

Teknik anchoring merupakan suatu pemberian pesan mental dengan sentuhan atau tindakan dan kata kata mengasosiasikan kejadian tertentu(Sutiyono, 2010). Anchoring merupakan suatu teknik sederhana, langsung mengarah, serta efektif (McKay, dkk., 2010). Dengan demikian, teknik ini lebih mengarah pada aspek mental atau emosi. Teknik Anchoring disebut juga penjangkaran emosi.

Teknik Anchoring sering digunakan oleh hipnoterapis dalam mengatasi berbagai persoalan mental dan emosi seseorang, seperti kritis kepercayaan diri, kecemasan berlebihan, rendahnya motivasi, dan sebagainya. Teknik ini menjadi jurus jitu bagi guru khususnya untuk mengatasi kebiasaan-kebiasaan buruk para peserta didik.

Dalam mengatasi kebiasaan peserta didik, teknik anchoring dilakukan guru dengan cara memasukkan suatu jangkar emosi kepada peserta didik tanpa disadari peserta didik bersangkutan. Dalam hal ini, jangkar emosi merupakan sugesti positif yang mudah diterima oleh pikiran bawah sadar, tersimpan dalam memori jangka panjang, serta menjadi realitas sehari-hari bagi peserta didik tersebut. Masalah belajar siswa yang dapat diatasi dengan teknik anchoring adalah sikap kurang jujur, suka ribut di kelas, kurang konsentrasi, rendah diri, lemah motivasi, merasa tidak pandai, dan masih banyak lagi. Penggunaan teknik anchoringjuga sangat sederhana sehingga hampir semua guru dapat menerapkannya tanpa kesulitan.

Ada beberapa langkah yang harus dilakukan dalam menerapkan teknik anchoring. Langkahlangkah untuk melakukan anchorpada kasus peserta didik yang kurang berprestasi, tidak mampu meningkatkan nilai akibat sulit berkonsentrasi, serta selalu membuat masalah saat di dalam kelas (Hakim, 2011).

a. Menanam Jangkar Emosi Visual

Saat pembelajaran berlangsung, guru bisa menanamkan anchor visual dengan mengatakan "Bagus", "Hebat", "Canggih", dan lainnya, sesekali guru perlu menata bola mata peserta didik dengan tatapan yang memberi kenyamanan. Agar teknik ini diingat siswa, lakukan cara ini setiap kali mengajar.

b. Menanamkan Jangkar Emosi Audio

Cara menanamkan jangkar emosi audio adalah pada saat menerangkan materi pembelajaran, lakukan perintah tersembunyi yang dikhususkan kepada peserta didik. Misalnya, "Seperti yang telah ibu katakan kepada Amir, belajar fisika dengan konsisten adalah sikap yang membanggakan". Dengan sering menyebut nama peserta didik yang memiliki kebiasaan buruk, maka pikiran bawah sadar peserta didik tersebut akan merasa diperhatikan. Sehingga, siswa akan secara tidak sadar mulai mengubah kebiasaan buruknya menjadi lebih positif.

c. Menanamkan Jangkar Emosi Kinestetik

Pada saat menerangkan materi pembelajaran, sesekali dekati peserta didik (misalnya Amir). Kemudian, sentuh atau tepuk dengan lembut bagian pundaknya (bisa kanan atau kiri). Ingatlah bahwa meskipun menyentuh Amir, kalimat yang digunakan harus ditujukan untuk seluruh peserta didik.

d. Menanamkan Jangkar Emosi Gustatory

Teknik ini dapat dilakukan di tengah-tengah proses pembelajaran. Langkah-langkah melakukan teknik jangkar emosi gustatory adalah berikut.

1) Lakukan pertanyaan yang mudah kepada siswa yang memiliki masalah belajar. Lakukan langkah ini dengan alamiah dan tanpa ada unsur paksaan.

2) Saat siswa yang memiliki masalah belajar tersebut menjawab dengan mendekati benar, berikan pujian dengan kata-kata positif, seperti "hebat", "luar biasa", dan "benar sekali". Kemudian berikan pertanyaan sekali lagi dengan porsi yang disesuaikan.

3) Setelah siswa yang memiliki masalah belajar tersebut menjawab dengan tepat, datangi dan berikan sesuatu (misalnya permen) kepada siswa tersebut. Lalu, ucapkan kata-kata sugesti positif kepadanya. Kata tersebut bisa seperti "Amir, permen yang nikmat ini baa berikan untukmu karena berhasil menjawab dengan benar".

Dalam melakukan anchoring, guru dapat melakukannya dengan memberi perhatian kepada individu maupun siswa secara keseluruhan. Cara untuk melakukan anchoringuntuk seluruh siswa dapat dengan mengatakan "Anak-anak, Bapa percaya bahwa kalian adalah calon penerus peradaban bangsa yang cerdas, Bapak sangat bangga terhadap kalian”. Kalimat ini harus diucapkan diiringi 
pandangan mata penuh harap kepada peserta didik dan memberi penekanan lebih pada kata cerdas. Kalimat ini sangat positif bagi perkembangan anak.

\section{KESIMPULAN}

Berdasarkan studi pustaka pelajaran fisika yang ada di Sekolah Menengah Atas merupakan Pelajaran yang tidak disukai oleh siswa hal ini terbukti dengan sebuah survey oleh zenius.net yang menempatkan fisika sebagai pelajaran yang paling tidak disukai dan Trends in Mathematics and Science Study (TIMSS) tahun 2011 untuk bidang sains, Indonesia berada diurutan ke-40 dari 42 negara dengan skor 406. Hypnoteaching hadir sebagai cara yang bisa diterapkan oleh guru dalam pembelajaran fisika. Hasil studi literatur membuktikan bahwa penerapan hypnoteaching ini terbukti membantu dalam mengatasi masalah belajar siswa dalam pembelajaran fisika.Hypnoteaching menyentuh masalah belajar fisika siswa tanpa disadari langsung oleh murid bersangkutan karena metode yang digunakan adalah alam bawah sadar siswa. Hypnoteaching secara literatur juga terbukti menjadi solusi dalam menghilangkan mental-block siswa saat memulai pembelajaran dan dapat digunakan oleh semua pendidik tanpa perlu belajar kepada ahli hipnotis. Hypnoteaching sangat mudah digunakan oleh guru dalam menghadapi murid dengan berbagai macam masalah belajar dalam fisika, mulai dari merasa bodoh, malas, merasa fisika tidak berguna, pesimis berlebih, dan masalah pembelajaran fisika lainnya. Hypnoteaching mudah diterapkan oleh semua guru karena tidak perlu menggunakan alat bantu apapun dalam melakukan metode ini sehingga sangat cocok untuk digunakan di seluruh pelosok sekolah indonesia.

\section{REFERENSI}

Achmadi, A. (1995). Filsafat Umum. Jakarta: Rajagrafindo Persada.

Elfiky, I. (2007). Terapi NLP. Jakarta: Hikmah.

Ghannoe. (2010). Buku Pintar NLP (Neuro Linguistic Programming). Yogyakarta: Flash Books.

Gunawan, A. W. (2009). Quantum Life Transformation. Jakarta: Gramedia Pustaka Utama.

Hakim, A. (2011). Dahsyatnya Pikiran Bawah Sadar. Jakarta: Visimedia.

Hamalik, O. (2005). Perencanaan Pengajaran Berdasarkan Pendekatan Sistem. Jakarta: PT Bumi Aksara.

Harris, C. (2003). NLP Made Easy. London: Element.

Jaya, N. T. (2010). Hypnoteaching "Bukan Sekedar Mengajar”. Bekasi: D-Brain.

L.S., Y. (2010). You Are the Real Personal Success! Formula NLP Praktis untuk Transformasi Menjadi Pribadi Sukses. Jakarta: Elex Media Komputindo.

Luzanovi, G. (1978). Suggestology and Outline of Suggeatopedy. New York: Gordon \& Breach.

Mahardika, D. (2015). Menerapkan Hypnostudying. Yogyakarta: DIVA Press.

McKay, dkk. (2010). How You Feel is up to You, The Power of Emotional Choise; Rahasisa Kekuatan Pilihan Emosi. Jakarta: Grasindo.

Navis, A. A. (2013). Hypnoteaching: Revolusi Gaya Mengajar untuk Melejitkan Prestasi Siswa. Jogjakarta: Ar-Ruzz Media.

Noer, M. (2010). Hypnoteaching for success learning. Yogyakarta: PT Pustaka Insan Madani.

Surachmad Winarno, d. (2003). Mengurai Benang Kusut Pendidikan. Jakarta: Transformasi.

Sutiyono, A. (2010). Dahsyatnya Hypnoparenting. Jakarta: Penebar Plus.

e-Journal : http://ejurnal.kpmunj.org 
Webe, A. (2010). Genius Inspirasi dan Motivasi yang Dapat Membangkitkan Sang Genius dalam Diri Anda. Jakarta: Gramedia Pustaka Utama.

Yustisia, N. (2012). Hypnoteaching. Yogyakarta: Ar-Ruzz Media. 